of his identification with a communicationally disordered parent, he lacks the ability to think clearly, comprehend communicate and solve problems in an increasingly complex world.

Thus, "breakdowns" occur at times of greatest stress (e.g., separation from home or cotwin, death of a grandparent, etc.) when his limited resources are overtaxed to the point of disorganization. By way of contrast, the cotwin has many more cognitive, communicational, and problem-solving skills available which, if stressed only " normally", are sufficient to carry him over life's hurdles.

Dr. Loren Mosher, Center for Studies of Schizophrenia, NIMH, 5600 Fishers Lane, Rockville, Maryland 20852, USA

\section{NOSOLOGICAL CLASSIFICATION OF ENDOGENOUS PSYCHOSES VIEWED FROM TWIN SURVEY}

\section{HISATOSHI MITSUDA, TOSHIAKI SAKAI}

Department of Neuropsychiatry, Osaka Medical College, Osaka-Takatsuki, Japan

In our study, we dealt with 12 pairs of $\mathrm{MZ}$ twins discordant for schizophrenia that we have collected not systematically. We divided all of the index cases into typical and atypical schizophrenia, to begin with, and compared the clinical features of their nonpsychotic cotwins. Consequently, we found the distinct differences between these two groups in regard, not only to personality traits, but also to clinical features of neurotic symptoms of the cotwins. In other words, there are considerable differences concerning clinical features (phenotype) between typical schizophrenia and atypical schizophrenia whenever the expression of genotype is not only complete but also incomplete. Such a tendency was noticed, to some extent, in the pedigree survey of schizophrenia carried out by Mitsuda. It is very interesting that these tendencies are confirmed by twin study, especially analyzing the incomplete discordant $\mathrm{MZ}$ twin cases.

Dr. Hisatoshi Mitsuda, Department of Neuropsychiatry, Osaka Medical College, Osaka-Takatsuki, Japan

\section{HEREDITY AND ENVIRONMENTAL FAGTORS IN THE DEVELOPMENT OF PSYCHOGENIG DISEASES}

\section{HEINZ SCHEPANK}

Psychosomatic Clinic, University of Heidelberg, German Federal Republic

Our objective is to evaluate the influence of heredity and environmental factors in the development of psychogenic illness: psychoneurotic symptoms, psychosomatic diseases, and neurotic traits of character. We applied psychoanalytic diagnostic methods and measures to neurotic twins from a psychotherapeutic outpatient clinic in Berlin (GFR). The sample comprises 2 I $\mathrm{MZ}$ pairs, I6 same-sex, and 13 opposite-sex DZ pairs. The Ioo subjects consist of 64 adults and 36 children or adolescents. All Ioo subjects were personally seen and psychologically examined. The zygosity determination was undertaken by P. E. Becker of Göttingen, GFR.

The mean intrapair difference of all $\mathrm{MZ}$ twin pairs amounts to $3.8 \mathrm{I}$ scaling points in a scored degree of severity of the neurosis; that of all DZ pairs to 5.00 points. The distribution of 657 neurotic symptoms in a chi-square table of the $21 \mathrm{MZ}$ and 29 DZ twin pairs shows that $32.7 \%$ of the symptoms are concordant in the $\mathrm{MZ}$ sample, but only $16.7 \%$ in the DZ sample. Both groups of twins differ in a statistically significant degree. Hereditary influence could be shown in the manifestation of neurotic depressive symptoms, maladaptive oral and aggressive behavior, as well as in schizoid behavior deviations. Hereditary factors play a role in the formation of the neurotic character structure.

Regarding the environmental pathogenic factors, subjects more heavily stressed in early childhood were found, on the whole, more severely neurotic in later life. In brief, three main groups of stressing environmental factors can be described: (1) emotional rejection, (2) an absence of key persons to love, and (3) special additional frustrations and conflicts. In the discordance analysis of $\mathrm{MZ}$ twins, the method of twin studies offers a unique chance to ascertain pathogenic environmental influences by means of a detailed biographic analysis.

Prof. Heinz Schepank, Psychosomatische Klinik der Universität, Vossstrasse 2, 69 Heidelberg, German Federal Republic 